\title{
Evaluación psiquiátrica, condición psicosocial y del estado mental de donante-receptor
}

\author{
Psychiatric evaluation, donor-recipient \\ psychosocial condition and state of mind
}

\author{
Judith González-Sánchez* \\ * Psiquiatría de Enlace. Jefe del Departamento de Consulta Externa. Instituto Nacional de Ciencias Médicas y Nutrición Salvador Zubirán.
}

\section{INTRODUCCIÓN}

Todos los pacientes y donadores que se encuentren en protocolo de trasplante renal deberán someterse a una evaluación de su condición sociocultural y económica por parte de una trabajadora social con conocimiento del tema. Por otro lado, también deberá llevarse a cabo la valoración de la condición psicosocial y estado mental del binomio por parte de un especialista en el tema con formación y/o experiencia en trasplantes.

La evaluación de estos aspectos, tanto en el donador como en el receptor, representa un recurso de amplio espectro para todo comité de trasplantes, ya que influyen no sólo en algunas condiciones médicoquirúrgicas del procedimiento, sino también en diversas situaciones con implicaciones psicosociales, éticas y legales. Es importante que los involucrados comprendan lo que representa someterse a un trasplante y el riesgo-beneficio que puede traer para ambos. En este sentido, la información completa y suficiente es imprescindible, ya que desempeña un papel esencial en aspectos éticos como la autonomía en la toma de decisiones y la capacidad de otorgar un consentimiento válidamente informado. Es importante resaltar que para el receptor mantener una adecuada condición mental interviene, por ejemplo, en el complejo proceso de la adherencia, fundamental para el éxito de la cirugía a largo plazo. Por otra parte, para el donador puede representar una forma de cuidar su autonomía, evaluando que sea capaz de decidir libremente con base en la comprensión y conocimiento adecuado, sin coerción de ningún tipo garantizando la transparencia del proceso. ${ }^{1-6}$

\section{Consideraciones generales}

- La valoración de la salud mental debe ser realizada por personal preparado para ello (psiquiatras y/o psicólogos). Sería deseable que el equipo esté constituido por ambos profesionales, lo ideal es que el médico especialista en salud mental participante sea psiquiatra de enlace.

- Los especialistas que intervengan en esta evaluación deben tener experiencia en trasplantes (conocimiento de los aspectos médicoquirúrgicos y psicosociales del procedimiento) o cumplir con algún taller específico del tema y/o entrenamiento práctico en algún centro de trasplantes bien estructurado.

- Las evaluaciones en salud mental deben por obligación incluir no sólo al receptor, sino también al donador. Es recomendable mantener estrecha comunicación con el equipo de Trabajo Social para tener una idea clara de los aspectos económicos y de dinámica familiar que pueden influir en la condición del binomio. 
- Se deben establecer mecanismos de evaluación y seguimiento bien sistematizados, así como criterios definidos de inclusión/exclusión. Deben ser asentados por escrito en el Protocolo de Trasplante de cada institución.

- Los especialistas en salud mental deben estar completamente integrados al Comité de Trasplantes, mantener un perfil estable y brindar información práctica con validez objetiva para todo el equipo multidisciplinario de forma tanto verbal como escrita. El resultado de las evaluaciones debe ser consignado de manera clara en el expediente clínico de cada uno de los involucrados.

\section{EVALUACIÓN DEL RECEPTOR}

Para realizar la valoración de la condición mental y psicosocial del receptor se sugiere lo siguiente:

1. Se sugiere que sea considerada dentro de las primeras evaluaciones al iniciar el protocolo, a fin de que se cuente con tiempo suficiente para identificar y dar manejo a situaciones psicosociales de mal pronóstico.

2. Deben realizarse, al menos, dos evaluaciones previas al procedimiento que permitan, a través de entrevista especializada, la identificación de las características del estado mental del receptor y el grado de preparación para el trasplante.

3. Los aspectos a evaluar en todo receptor renal deben ser los siguientes: ${ }^{2,3,6-8}$

a) Capacidad de comprensión (capacidad cognitiva): se debe identificar específicamente la posibilidad de algún tipo de inteligencia insuficiente ( $p$. ej. retraso mental) o deterioro cognitivo de gravedad variable (p. ej. procesos demenciales) que pueda interferir con la capacidad de comprensión. Se realizará con base en criterios clínicos psiquiátricos. Será necesaria, en casos dudosos, la aplicación de pruebas psicológicas para establecer coeficiente intelectual preciso y/o baterías neurocognitivas para confirmar el nivel de funcionamiento real.

b) Rasgos/trastornos de personalidad de riesgo: corresponden a formas de ser que pueden interferir con la adherencia terapéutica, alterar la relación médico-paciente o dar indicios de coerción. Se sugiere buscar perfiles de inseguridad, pasividad, rigidez, obsesividad, inestabilidad, impulsividad, agresividad o tendencias abusivas. Se identificarán, de primera instancia, a través de entrevista clínica basada en diagnósticos psiquiátricos. En casos dudosos o cuando se trate de una donación proveniente de un donador no relacionado, sería deseable aplicar pruebas psicológicas de personalidad.

c) Padecimientos psiquiátricos: se debe identificar la presencia de enfermedades mentales específicas tales como: trastornos del estado de ánimo [depresión mayor (incluyendo riesgo suicida) o trastorno bipolar], padecimientos ansiosos (trastorno de ansiedad generalizada, ataques de pánico y fobias específicas), psicosis agudas y/o crónicas (delirium, esquizofrenia, trastornos delirantes) y otros como trastorno de estrés postraumático y trastorno obsesivo-compulsivo. La evaluación se llevará a cabo a través de entrevista especializada basada en diagnósticos psiquiátricos y deberá establecerse, en la medida de lo posible, si éstos son primarios o secundarios a la enfermedad de base y/o tratamientos requeridos para la misma (medicamentos, anemia, hemodiálisis, etc.). En casos dudosos sería deseable aplicar instrumentos de evaluación tales como escala hospitalaria de ansiedad-depresión (HAD), cuestionario de salud del paciente (PHQ-9), inventario de depresión de Beck (BDI), etcétera. En este punto se requiere investigar en torno a la reacción emocional ante la enfermedad y la opción de trasplante, estableciendo tanto el diagnóstico de acuerdo con criterios psiquiátricos como el manejo que ha recibido para ello y/o el mecanismo personal a través del cual lo ha enfrentado.

d) Consumo de sustancias psicoactivas: se debe establecer el patrón de consumo del paciente (histórico y/o actual) de acuerdo con los criterios de la OMS (nulo, experimental, ocasional, frecuente, perjudicial/abuso o dependencia) de sustancias tales como tabaco, alcohol, benzodiacepinas, cannabis, cocaína, inhalantes, anfetaminas, opiáceos, etc. Es necesario investigar los factores de mal pronóstico tales como: personalidades inestables-impulsivas, antecedentes familiares de consumo, tener diversas dependencias, presentar diagnósticos duales, tener problemas en la red primaria de apoyo y/o haber tenido fracaso al someterse a programas contra adicciones. La evaluación se llevará a cabo a través de entrevista especia- 
lizada basada en diagnósticos psiquiátricos 0 aplicar la prueba de tamizaje alcohol, Smoking and Substance Involvement Screening Test (ASSIST) validada para la población mexicana. En caso de encontrarse problemas en este rubro se deberá iniciar de inmediato el manejo específico de acuerdo con la gravedad de consumo (medicamentos, psicoterapia, grupos de autoayuda, etcétera).

4. Los aspectos a evaluar para conocer el grado de preparación para el trasplante por parte del receptor deben ser los siguientes:

a) Comprensión y nivel de información real: se debe investigar el conocimiento que el paciente tiene de todos los aspectos relacionados como son el tipo de enfermedad, las características del trasplante (tiempos de duración del protocolo, de la estancia hospitalaria y del periodo de recuperación), la variante de cirugía a la que se someterá (incluyendo costos de la misma y posibles complicaciones), manejo posterior a la intervención (seguimiento médico, dieta, tipo de medicamentos y efectos secundarios, cuidados especiales, convivencia con mascotas). La evaluación se llevará a cabo a través de entrevista semiestructurada, la cual se basa en el conocimiento completo del tema por parte del entrevistador. En caso de que el nivel de información sea insuficiente y/o inadecuado, se debe comentar con el equipo de trasplante para que subsane esta situación. Se puede realizar intervención psicoeducativa en caso de que las características socioculturales estén condicionando problemas de comunicación pacienteequipo de salud.

b) Nivel de adherencia: hace referencia al grado en que el paciente sigue las indicaciones emitidas por el equipo de salud. Deben investigarse aspectos como la toma de medicamentos (nombre del fármaco, horarios, efectos secundarios), cambios recomendados en el estilo de vida (manejo de terapia substitutiva, seguimiento de la dieta y/o restricción hídrica, práctica de ejercicio, control de peso, consumo de sustancias), realización de análisis y estudios así como la asistencia regular a sus diversas consultas médicas. La evaluación se llevará a cabo a través de entrevista semiestructurada, la cual se basa en el conocimiento completo del tema por parte del entrevistador. Se sugiere contrastar las respuestas preguntando de forma directa a los acompañantes, médicos tratantes y/o consulta directa del expediente clínico. Se puede brindar intervención psicoeducativa para reforzar la importancia de continuar con el apego a indicaciones posterior al trasplante.

c) Red de apoyo emocional, familiar, social y económico: se refiere al soporte psicosocial con el que cuenta el paciente para enfrentar el procedimiento. Dicha información habitualmente es evaluada por el área de Trabajo Social, pero debe ser contrastada por el especialista en salud mental, pues los problemas en estos aspectos suelen ser generadores de estrés y psicopatología. Es necesario investigar el tipo de familia que tiene, los miembros que le apoyan, el nombre del responsable legal que tomaría las decisiones en caso de que el paciente no pueda hacerlo y la forma en que la enfermedad ha cambiado sus relaciones interpersonales. También se debe investigar sobre la seguridad social con la que cuenta para hacer frente a los costos de la cirugía y la inmunosupresión. Por otro lado, debe establecerse si el receptor tiene apoyos adicionales (asociaciones, grupos religiosos, etc.) y si sufre algún problema familiar, social y/o económico que le preocupe de manera especial (divorcios, herencias, reconocimiento de hijos, hipotecas, préstamos, problemas para acceder a terapia substitutiva, etc.). La evaluación se llevará a cabo a través de entrevista semiestructurada, la cual se basa en el conocimiento completo del tema por parte del entrevistador. Se sugiere complementarla a través de la comunicación directa con el área de Trabajo Social de Trasplante.

d) Creencias, influencias y/o expectativas: es necesario investigar propositivamente en torno a alguna concepción personal y/o influencia cultural-religiosa que pueda interferir con el trasplante (presión familiar, social y/o religiosa). Se debe indagar en torno a las expectativas personales y de su entorno en relación con los resultados del procedimiento, así como las dudas, deseos y temores no expresados en el contexto del proceso que está viviendo. La evaluación se llevará a cabo a través de entrevista semiestructurada, la cual se basa en el conocimiento completo del tema por parte del entrevistador. Se sugiere complementarla a través de la comunicación directa con el área de Trabajo Social de Trasplante. 
e) Calidad de vida actual: se refiere al grado de impacto que ha tenido la enfermedad en los diversos aspectos de la vida diaria del receptor. Suele brindar información valiosa para realizar intervenciones psicosociales tempranas que puedan mejorar el proceso de rehabilitación posterior a la cirugía. Se debe investigar el grado de funcionalidad física, emocional, familiar y social (actividad laboral, escolar, recreativa, etc.) que tiene el receptor, así como su grado de dependencia actual. Se sugiere incentivar al paciente a buscar el máximo de autonomía posible tanto como lo permitan sus condiciones físicas. La evaluación se llevará a cabo a través de entrevista semiestructurada, la cual se basa en el conocimiento completo del tema por parte del entrevistador. Se sugiere aplicar el cuestionario SF-36, instrumento validado en población mexicana que evalúa la calidad de vida en población adulta con enfermedades crónicas.

\section{CONTRAINDICACIONES}

Las contraindicaciones para realizar un trasplante por condiciones de la salud mental del receptor son muy pocas. ${ }^{2}$ En la mayoría de las ocasiones se habla de factores de mal pronóstico o contraindicaciones relativas, ya que se trata de circunstancias que pueden ser superadas por el paciente con intervenciones específicas por parte del equipo de psicología/psiquiatría. . $^{3,4,6,7} \mathrm{Si}$ a pesar del manejo psicosocial éstas no se solventan, podrían constituir un inconveniente para que el trasplante se lleve a cabo. Se sugiere que la decisión final ante una controversia en este sentido deberá establecerse en TODOS LOS CASOS posterior a la discusión en el seno del Subcomité de Trasplante Renal.

Se han considerado como factores de mal pronóstico o contraindicación las siguientes:

1. Dificultades para comprender la información debido a problemas cognitivos permanentes (inteligencia limitada, proceso demencial) que suelen interferir con la adherencia y el principio de autonomía. En este caso se sugiere evaluar tanto las características pronósticas del paciente como las de su red de apoyo psicosocial, a fin de ser presentado a consideración del comité. La ley hace referencia a que el receptor debe tener un buen nivel de información para someterse a la cirugía; sin embargo, el hecho de negarle esta oportunidad por ser una persona en condición de vulnerabilidad podría integrarse como discriminación.

2. Presencia de sintomatología psiquiátrica aguda y/o crónica agudizada que interfiera con la comprensión y/o el autocuidado. En este caso se debe iniciar tratamiento específico (medicamentos, psicoterapia y/o internamiento) y se reevaluará su condición periódicamente hasta mejoría. El psiquiatra debe ser el responsable de dosificar de manera correcta los psicofármacos de acuerdo con las condiciones renales, así como de evitar los que pudieran causar mayor nefrotoxicidad. Una vez controlada la condición puede avalarse el trasplante.

3. Consumo actual de sustancias psicoactivas de cualquier tipo. Se solicitará un tiempo de abstinencia de seis a 12 meses, dependiendo de los factores de mal pronóstico con los que cuente el receptor. En caso de presentar trastorno por consumo de la sustancia deberá integrarse a programa formal de tratamiento (AA, NA, clínica contra el tabaquismo, etc.) para poder proceder al trasplante.

4. Conductas que evidencien con toda claridad problemas de apego al protocolo (inasistencia a sus citas generales, inadecuado seguimiento de las indicaciones higiénico/dietéticas, toma irregular de medicamentos, conductas de alto riesgo, etc.). En este caso se trabajará psicológicamente con el paciente hasta que demuestre seis meses de mejoría en la adherencia.

5. Problemas socioeconómicos tales como disfunción familiar grave, presión del grupo social para trasplantarse, creencias religiosas contrarias al procedimiento $\mathrm{y} / \mathrm{o}$ seguridad social insuficiente para costear la inmunosupresión. Ante estas condiciones se deberá trabajar en conjunto con el grupo de Trabajo Social para buscar opciones y realizar las intervenciones familiares necesarias para solventar la situación.

6. Evidencia de conductas por parte del paciente, donador y/o familiares que vayan en contra de la ética médica o la ley tales como la coerción de cualquier tipo (emocional, laboral, religiosa, etc.) o la compraventa del proceso. Estos casos deberán discutirse siempre en el contexto del Subcomité de Trasplante Renal.

\section{EVALUACIÓN DEL DONADOR}

Para realizar la valoración de la condición mental y psicosocial ${ }^{1,2}$ del donador se sugiere lo siguiente: 
1. Se sugiere que sea considerada dentro de las primeras evaluaciones al iniciar el protocolo, a fin de que se cuente con tiempo suficiente para identificar y dar manejo a situaciones psicosociales de mal pronóstico.

2. Deben realizarse, al menos, dos valoraciones previas al procedimiento que permitan, a través de entrevista especializada, la identificación de las características del estado mental del donador y el grado de preparación para el trasplante. En caso de vivo no relacionado, la evaluación habitualmente es más compleja.

3. Los aspectos a evaluar en un donador renal potencial deben ser los siguientes:1,8-17

a) Capacidad de comprensión (capacidad cognitiva): es necesario identificar específicamente la posibilidad de algún tipo de inteligencia insuficiente $(p$. ej. retraso mental) $o$ deterioro cognitivo de gravedad variable (p. ej. procesos demenciales) que pueda interferir con la capacidad de comprensión. Ante la más mínima evidencia clínica, es obligatoria la aplicación de pruebas psicológicas para establecer coeficiente intelectual preciso y/o baterías neurocognitivas para confirmar el nivel de funcionamiento real. Si se comprueban problemas en este aspecto, no podrá proceder la donación por cuestiones éticas y legales.

b) Rasgos/trastornos de personalidad de riesgo: corresponden a formas de ser que pueden interferir con el autocuidado posterior al trasplante, condicionar problemas de relación donador-receptor o dar indicios de una posible coerción. Se sugiere buscar perfiles de inseguridad, pasividad, inestabilidad, impulsividad, agresividad, tendencias abusivas o francas conductas dependientes. Se identificarán, de primera instancia, a través de entrevista clínica basada en diagnósticos psiquiátricos. En casos dudosos o cuando se trate de un donador no relacionado y/o altruista, se deberán aplicar pruebas psicológicas de personalidad al candidato.

c) Padecimientos psiquiátricos: es necesario detectar la presencia de enfermedades mentales específicas tales como: trastornos del estado de ánimo [depresión mayor (incluyendo riesgo suicida) o trastorno bipolar], padecimientos ansiosos (trastorno de ansiedad generalizada, ataques de pánico y fobias específicas), psicosis agudas y/o crónicas (delirium, esquizofrenia, trastornos delirantes) y otros como trastorno de estrés postraumático y trastorno obsesivo-compulsivo. La evaluación se llevará a cabo a través de entrevista especializada basada en criterios diagnósticos DSMV y deberá establecerse si estos son primarios o secundarios a alguna enfermedad de base y/o tratamientos requeridos para la misma. En casos dudosos sería deseable aplicar instrumentos de evaluación tales como escala hospitalaria de ansiedad-depresión (HAD), cuestionario de salud del paciente (PHQ-9), inventario de depresión de Beck (BDI), etcétera. En este punto es necesario investigar en torno a la respuesta emocional ante todo lo que implica la posibilidad de donar, ser evaluado y recibir el visto bueno de las diversas especialidades. Cuando aplique, deberá establecerse el diagnóstico de acuerdo con criterios diagnósticos DSMV así como el manejo que ha recibido para ello y/o el mecanismo personal a través del cual lo ha enfrentado. ${ }^{18}$

d) Consumo de sustancias psicoactivas: se debe establecer el patrón de consumo del posible donador (histórico y/o actual) de acuerdo con los criterios de la OMS (nulo, experimental, ocasional, frecuente, perjudicial/abuso 0 dependencia) de sustancias tales como tabaco, alcohol, benzodiacepinas, cannabis, cocaína, inhalantes, anfetaminas, opiáceos, etc. Deben investigarse los factores de mal pronóstico tales como: personalidades inestables-impulsivas, antecedentes familiares de consumo, tener diversas dependencias, presentar diagnósticos duales, tener problemas en la red primaria de apoyo y/o haber tenido fracaso al someterse a programas contra adicciones. La evaluación se llevará a cabo a través de entrevista especializada basada en diagnósticos psiquiátricos o aplicar la prueba de tamizaje alcohol, Smoking and Substance Involvement Screening Test (ASSIST) validada para la población mexicana. En caso de detectar problemas en este rubro se deberá iniciar de inmediato el manejo específico de acuerdo a la gravedad de consumo (medicamentos, psicoterapia, grupos de autoayuda, etc.) quedando suspendida la donación, en principio, temporalmente.

1. Los aspectos a evaluar para conocer el grado de preparación para el trasplante por parte del donador deben ser los siguientes: 
a) Comprensión y nivel de información real: se requiere investigar el conocimiento que el posible donador tiene de todos los aspectos relacionados como son las características del procedimiento (tiempos de duración del protocolo, estancia hospitalaria y periodo de recuperación antes de reintegrarse a sus actividades habituales), la variante de cirugía a la que se someterá (incluyendo costos de la misma y posibles complicaciones), manejo posterior a la intervención (seguimiento médico, dieta, actividades físicas en general, cuidados especiales y riesgos reales de desarrollar una enfermedad en función directa del hecho de donar). También es importante que el posible donador cuente con información en torno a otras opciones de tratamiento para el paciente y el pronóstico de cada una de ellas, a fin de que tenga mayor claridad en el momento de tomar decisiones. La evaluación se llevará a cabo a través de entrevista semiestructurada, la cual se basa en el conocimiento completo del tema por parte del entrevistador. En caso de que el nivel de información sea insuficiente y/o inadecuado es necesario comentar con el equipo de trasplante para que subsane esta situación. Se puede realizar intervención psicoeducativa en caso de que las características socioculturales estén condicionando problemas de comunicación paciente-equipo de salud.

b) Relación real/emocional con el receptor: hace referencia al tipo de vínculo existente entre $\mathrm{D}-\mathrm{R}$ independiente de la relación que se tenga con él. En este sentido debe establecerse con claridad si está biológicamente relacionado, emocionalmente relacionado, no relacionado o altruista, ya que esto determinará la profundidad de la evaluación. Debe investigarse el tiempo de conocerse, cómo se han llevado, emociones involucradas, si han existido conflictos entre ellos y como los han solventado, favores recibidos, deudas contraídas. También se debe preguntar en torno a las motivaciones para donar buscando la posibilidad de coerción, la cual puede ser francamente evidente o aparecer encubierta. La evaluación se llevará a cabo a través de entrevista semiestructurada, la cual se basa en el conocimiento completo del tema por parte del entrevistador. Se sugiere contrastar las respuestas preguntando de forma directa a los acompañantes (familiares y/o amigos), médicos tratantes, profesionales del área de Trabajo Social y/o consulta directa del expediente clínico. Se puede brindar intervención psicoeducativa para reforzar la importancia de que sea una donación altruista y garantizar la libre decisión abriendo la posibilidad de cambiar de opinión en cualquier momento sin repercusiones de ninguna especie.

c) Red de apoyo emocional, familiar, social y económico: se refiere al soporte psicosocial con el que cuenta el donador para enfrentar su decisión. Dicha información habitualmente es evaluada por el área de Trabajo Social, pero debe ser contrastada por el especialista en salud mental, pues los problemas en estos aspectos suelen ser generadores de estrés y psicopatología. Es necesario investigar el tipo de familia que tiene, los miembros que le apoyan, el nombre del responsable legal que tomaría las decisiones en caso de que el donador no pueda hacerlo y si han existido repercusiones en la dinámica familiar (negativas o positivas) derivadas de su decisión de donar. También se debe investigar sobre la seguridad social con la que cuenta para hacer frente al procedimiento, si ha verificado que se le otorgará incapacidad y/o corre riesgo de perder su empleo. Por otro lado, debe establecerse si el donador tiene apoyos adicionales (asociaciones, grupos religiosos, etc.) o si sufre algún problema familiar, social y/o económico que le preocupe de manera especial (divorcios, herencias, reconocimiento de hijos, hipotecas, préstamos, etc.). La evaluación se llevará a cabo a través de entrevista semiestructurada, la cual se basa en el conocimiento completo del tema por parte del entrevistador. Se sugiere complementarla a través de la comunicación directa con el área de Trabajo Social de Trasplantes y/o realizar una entrevista familiar para verificar la información.

d) Creencias, influencias y/o expectativas: se requiere investigar propositivamente en torno a alguna concepción personal y/o situación sociocultural que pueda influir en la decisión de donar (presión familiar, social y/o religiosa). Se debe indagar en torno a las expectativas personales y de su entorno en relación con los resultados del procedimiento (tanto para el receptor como para el donador), así como las dudas, deseos y temores no expresados en el contexto del proceso que está viviendo. La evaluación se llevará a cabo a través de entrevista semies- 
tructurada, la cual se basa en el conocimiento completo del tema por parte del entrevistador. Sería deseable complementarla a través de la comunicación directa con el área de Trabajo Social de Trasplante y/o realizar una entrevista familiar para verificar información.

e) Calidad de vida actual: se refiere al grado de funcionalidad basal que tiene el posible donador en los diversos aspectos de su vida diaria. Suele brindar información valiosa para realizar intervenciones psicosociales tempranas que puedan mejorar el proceso de rehabilitación posterior a la cirugía. Se requiere investigar el grado de funcionalidad física, emocional, familiar y social que tiene el donador evaluando el posible impacto que podría tener la donación en estos aspectos. La evaluación se llevará a cabo a través de entrevista semiestructurada, la cual se basa en el conocimiento completo del tema por parte del entrevistador. Se sugiere aplicar el cuestionario SF-36, instrumento validado en población mexicana que evalúa la calidad de vida en población adulta con enfermedades crónicas.

\section{CONTRAINDICACIONES}

Las contraindicaciones para realizar un trasplante en función de la condición mental del donador suelen derivarse de aspectos éticos fundamentalmente., ${ }^{1,2,5,6} \mathrm{Al}$ igual que con el receptor, se habla también de factores de mal pronóstico o contraindicaciones relativas que, tratándose de una persona sana que se enfrentará a una cirugía por una situación altruista, debe ser obligación del equipo de salud mental colaborar con el hecho de que no sean minimizados, pues debe velarse por su estabilidad en todo momento. ${ }^{19,20}$ Ante su presencia deberán recibir intervenciones específicas por parte del equipo de psicología/psiquiatría y si a pesar del manejo psicosocial éstas no se solventan, constituirán un inconveniente definitivo para que el trasplante se lleve a cabo. Se sugiere que la decisión final ante una controversia en este sentido deberá establecerse en TODOS LOS CASOS posterior a la discusión en el seno del Subcomité de Trasplante Renal.

Se han considerado como factores de mal pronóstico o contraindicación relativa o total: ${ }^{19-22}$

1. Dificultades para comprender la información debido a problemas cognitivos permanentes (inteligencia limitada, proceso demencial) que incapacita la libre decisión. En este caso se habla de una contraindicación absoluta con base en aspectos éticos y legales, por lo que deberá informarse tanto al donador, receptor y al resto del equipo de trasplante a fin de que no se prosiga con el protocolo.

2. Presencia de sintomatología psiquiátrica aguda reversible (problemas ansiosos/depresivos) que interfiera con la comprensión y/o el autocuidado. En este caso se debe iniciar tratamiento específico (medicamentos, psicoterapia y/o internamiento) y se reevaluará su condición periódicamente hasta mejoría a fin de determinar si se encuentra apto para donar. En caso de enfermedades crónicas que afecten el juicio para decidir (psicosis agudas y/o crónicas así como trastornos graves de personalidad) no deberá considerarse como donador viable. Es responsabilidad absoluta del equipo de salud mental supervisar esta situación.

3. Consumo actual de sustancias psicoactivas de cualquier tipo. Se solicitará un tiempo de abstinencia de seis a 12 meses, dependiendo de los factores de mal pronóstico con los que cuente el donador. En caso de presentar trastorno por consumo de la sustancia deberá integrarse a programa formal de tratamiento (AA, NA, clínica contra el tabaquismo, etc.) antes de considerarlo para la donación.

4. Conductas que evidencien con toda claridad que el posible donador no desea donar, pero no lo ha querido o podido expresar libremente. Ejemplo de ello sería inasistencia a sus citas médicas, falta de realización de los estudios sugeridos, incumplimiento en las recomendaciones higiénico-dietéticas para bajar de peso y/o suspender el consumo de sustancias psicoactivas, etc. En este caso se debe realizar una intervención psicosocial directa y confrontar de manera empática la interpretación que se tiene de su conducta. Debe ofrecerse siempre la información en torno al derecho que tiene de decidir libremente sin repercusiones de ningún tipo y proporcionar apoyo emocional ante su decisión.

5. Problemas de relación donador-receptor tales como conflictos familiares (antiguos o vigentes).

6. Problemas socioeconómicos tales como disfunción familiar grave, presión del grupo social para donar, creencias religiosas contrarias al procedimiento y/o posible repercusión negativa en su solvencia económica a futuro (pérdida de empleo). Ante estas condiciones se deberá trabajar en conjunto con el grupo de Trabajo Social para búsqueda de opciones y realizar las intervenciones familiares necesarias para solventar la situación. En principio 
se constituyen como factores de mal pronóstico, pero pueden llegar a constituir contraindicaciones absolutas.

7. Evidencia de conductas por parte del paciente, donador y/o familiares que vayan en contra de la ética médica o la ley tales como la coerción de cualquier tipo (emocional, laboral, religiosa, etc.) o la compra-venta del proceso. Estos casos deberán discutirse siempre en el contexto del Subcomité de Trasplante Renal.

\section{REFERENCIAS}

1. Sawinski D, Locke JE. Evaluation of kidney donors: core curriculum 2018. Am J Kidney Dis. 2018; 71 (5): 737-747. doi: 10.1053/j.ajkd.2017.10.018. PubMed PMID: 29336856.

2. Faeder S, Moschenross D, Rosenberger E, Dew MA, DiMartini A. Psychiatric aspects of organ transplantation and donation. Curr Opin Psychiatry. 2015; 28 (5): 357-364.

3. Kalra G, Desousa A. Psychiatric aspects of organ transplantation. Int J Org Transplant Med. 2011; 2 (1): 9-18. Available in: www. ljotm.com

4. Maldonado JR, Sher Y, Lolak S, Swendsen H, Skibola D, Neri $E$ et al. The Stanford integrated psychosocial assessment for transplantation: a prospective study of medical and psychosocial outcomes. Psychosom Med. 2015; 77 (9): 1018-1030.

5. De Frutos MA. Ética en donación de órganos: una alianza rentable. Cuad Med Forense. 2015; 21 (1-2): 50-56.

6. Casares M. Aspectos éticos de la donación renal de vivo. Nefrología. 2010; 30 (Suppl 2): 14-22. Disponible en: http:// www.revistanefrología.com

7. Kumnig M, Jowsey-Gregoire, S. Preoperative psychological evaluation of transplant patients: challenges and solutions. Transplant Research and Risk Management. 2015; 7: 35-43.

8. Gumabay FM, Novak M, Bansal A, Mitchell M, Famure O, Kim SJ et al. Pre-transplant history of mental health concerns, nonadherence, and post-transplant outcomes in kidney transplant recipients. J Psychosom Res. 2018; 105: 115-124.

9. Iacoviello B, Shenoy A, Hunt J, Filipovic-Jewell Z, Haydel B, LaPointe Rudow D. A Prospective study of the reliability and validity of the live donor assessment tool. Psychosomatics. 2017; 58: 519-526. Available in: www.psychosomaticsjournal.org

10. Massey EK, Timmerman L, Ismail SY, Duerinckx N, Lopes A, Maple $\mathrm{H}$. The ELPAT living organ donor psychosocial assessment tool (EPAT): from 'what' to 'how' of psychosocial screening - a pilot study. Transpl Int. 2018; 31 (1): 56-70. doi: 10.1111/tri.13041. PubMed PMID: 28850737.

11. Kook YWA, Shenoy A, Hunt J, Desrosiers F, Gordon-Elliott JS, Jowsey-Gregoire S. Multicenter investigation of the reliability and validity of the live donor assessment tool as an enhancement to the psychosocial evaluation of living donors. Am J Transplant.
2019; 19 (4): 1119-1128. doi: 10.1111/ajt.15170. PubMed PMID: 30414243.

12. Graham JM, Courtney AE. The adoption of a one-day donor assessment model in a living kidney donor transplant program: a quality improvement project. Am J Kidney Dis. 2018; 71 (2): 209-215. doi: 10.1053/j.ajkd.2017.07.013. PubMed PMID: 29150247.

13. Weng FL, Morgievich MM, Kandula P. The evaluation of living kidney donors: how long is too long? Am J Kidney Dis. 2018; 72 (4): 472-474. doi: 10.1053/j.ajkd.2018.07.001. PubMed PMID: 30244695 .

14. Moore DR, Serur D, Rudow DL, Rodriguez JR, Hays R, Cooper M. Living donor kidney transplantation: improving efficiencies in live kidney donor evaluation--recommendations from a consensus conference. Clin J Am Soc Nephrol. 2015; 10 (9): 1678-1686. doi: 10.2215/CJN.01040115. PubMed PMID: 26268509.

15. Rudow DL, Swartz K, Phillips C, Hollenberger J, Smith T, Steel $\mathrm{JL}$. The psychosocial and independent living donor advocate evaluation and post-surgery care of living donors. J Clin Psychol Med Settings. 2015; 22 (2-3): 136-49. doi: 10.1007/s10880-0159426-7. PubMed PMID: 26293351.

16. Shenoy A. The psychosocial evaluation of live donors. In: Sher Y, Maldonado JR (editors). Psychosocial care of end-stage organ disease and transplant patients. Cham: Springer International Publishing; 2019. pp. 49-59.

17. Conrad R, Kleiman A, Rambau S, Wegener I, Mücke M, DolscheidPommerich $\mathrm{RC}$ et al. Psychosocial assessment of living kidney donors: what implications have temperament and character for decision-making? Compr Psychiatry. 2016; 67: 1-8. doi: 10.1016/j. comppsych.2016.02.007. PubMed PMID: 27095327.

18. Holscher CM, Leanza J, Thomas AG, Waldram MM, Haugen CE, Jackson KR. Anxiety, depression, and regret of donation in living kidney donors. BMC Nephrol. 2018; 19 (1): 218. doi: 10.1186/s12882-018-1024-0. PubMed PMID: 30180815.

19. Jacobs Ch, Gross C, Messersmith E, Hong B, Gillespie B et al. Emotional and financial experiences of kidney donors over the past 50 years: the RELIVE study. Clin J Am Soc Nephrol. 2015; 10 (12): 2221-2231.

20. Timmerman L, Timman R, Laging M, Zuidema WC, Beck DK et al. Predicting mental health after living kidney donation: the importance of psychological factors. Br J Health Psychol 2016; 21 (3): 533-554.

21. Tong A, Chapman JR, Wong G, Kanellis J. The motivations and experiences of living kidney donors: a thematic synthesis. Am J Kidney Dis. 2012; 60 (1): 15-26.

22. Ralph AF, Butow P, Hanson CS, Chadban SJ, Chapman JR, Craig JC et al. Donor and recipient views on their relationship in living kidney donation: thematic synthesis of qualitative studies. Am J Kidney Dis. 2017; 69 (5): 602-616.

Correspondencia:

Dra. Judith González-Sánchez

E-mail: judith.gonzalezs@incmnsz.mx 